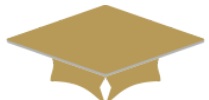

MEDRESEARCH

www.medresearch.in

\title{
Prevalence and associated risk factors of depression among housewives in rural Saharanpur, Uttar Pradesh, India
}

\author{
Vikramaditya B. ${ }^{1}$, Kumar Jha A. ${ }^{2 *}$, Kumar S. ${ }^{3}$, M. $^{4}$, Joshi H. ${ }^{5}$ \\ DOI: https://doi.org/10.17511/ijphr.2020.i1.02
}

1 Bibhava Vikramaditya, Assistant Professor, Department of Community Medicine, SMMH Government Medical College, Saharanpur, Uttar Pradesh, India.

2* Amit Kumar Jha, Professor, Department of Community Medicine, SMMH Government Medical College, Saharanpur, Uttar Pradesh, India.

3 Sanjeev Kumar, Associate Professor and Head, Department of Community Medicine, SMMH Government Medical College, Saharanpur, Uttar Pradesh, India.

${ }^{4}$ Manjeeta , Junior Resident, Department of Community Medicine, SMMH Government Medical College, Saharanpur, Uttar Pradesh, India.

5 Hari Shankar Joshi, Professor and Head, Department of Community and Family Medicine, All India Institute Of Medical Sciences, Gorakhpur, Uttar Pradesh, India.

Introduction: Depression is the most common mental disorder. Women and the elderly have shown greater vulnerability to depression. Additional responsibilities due to modernization in rural areas have to lead to increased stress and tension among housewives. Limited data is available on depression among housewives in rural India especially Uttar Pradesh. Objective: To assess the prevalence and risk factors of depression among housewives in the rural area. Methods: The study was done in five villages of Saharanpur, Uttar Pradesh from November 2018 to October 2019. A total of 500 housewives were selected by systematic random sampling. Interviews were conducted by the house to house visits. Depression was evaluated using the self-reported instrument Patient Health Questionnaire-9 (PHQ-9). Results: The prevalence of depression was found to be $18 \%$. There was an increasing trend in the prevalence of depression in the middle age group. The increasing level of education, marriage, better socio-economy, economic independence and absence of co-morbid conditions had a lower prevalence of depression. Conclusion: Housewives should be educated about warning signs and symptoms of depression and motivated to seek professional help.

Keywords: Housewives, Depression, Rural, Saharanpur

Corresponding Author

Amit Kumar Jha, Professor, Department of Community Medicine, SMMH Government Medical College, Saharanpur, Uttar Pradesh, India. Email: amitkumarjha97din@gmail.com
How to Cite this Article

Vikramaditya B, Jha AK, Kumar S, Manjeeta, Joshi HS. Prevalence and associated risk factors of depression among housewives in rural Saharanpur, Uttar Pradesh, India. Public Health Rev Int J Public Health Res. 2020;7(1):7-13.

\section{Available From}

https://publichealth.medresearch.in/index.php/ijphr/ article/view/132
To Browse

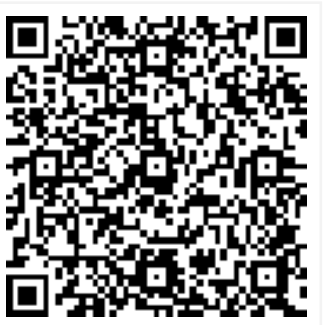

Manuscript Received 2020-01-30

Conflict of Interest No
Review Round 1 2020-02-09

Funding

$\mathrm{Nil}$

Review Round 2
2020-02-14
Ethical Approval
Yes

Review Round 2

Yes
Review Round 3

Plagiarism X-checker $8 \%$
Accepted 2020-02-19

(C) 2020 by Bibhava Vikramaditya, Amit Kumar Jha, Sanjeev Kumar, Manjeeta, Hari Shankar Joshi and Published by Siddharth Health Research and Social Welfare Society. This is an Open Access article licensed under a Creative Commons Attribution 4.0 International License https://creativecommons.org/licenses/by/4.0/ unported [CC BY 4.0]. 


\section{Introduction}

In the current scenario, stress is increasing in our community and hence mental illnesses are showing an increasing trend. Though mental illness can occur at any age, depression and anxiety disorders are quite common problems for young people. It can affect our thoughts, feelings, actions, and memory. There are a number of mental illnesses, which include: Depression, Anxiety, Psychosis, Eating disorders, Bipolar disorder, alcohol, and substance abuse. Depression is the most common mental disorder. Often depression is underrecognized and under-treated among adults. Overlooking depression can have tragic consequences as depression is associated with increased risk of suicide and a higher risk for mental disorders, substance abuse, physical disorders, and co-morbidities. They further reduce a patient's quality of life. Depression accounted for $40.5 \%$ of years lived with disability caused by mental and substance use disorders according to the Global Burden of Disease Study [1]. Depression presents with depressed mood, loss of interest or pleasure, decreased energy, disturbed sleep or appetite, and poor concentration. It differs from usual mood fluctuations and short-lived emotional responses to challenges in everyday life. When long-lasting it may become a serious health condition and causes the affected person to suffer at work, school or family. Depression affects the way of thinking, feeling and functioning in everyday life. It is a mental health disability that is most of the time created due to individual problems, organizational problems or societal problems. Initial symptoms may be persistent sadness, hopelessness, worthlessness, helplessness, restlessness. Depression often presents in the form of physical complaints that appear to be medically unexplained. The studies on the prevalence of depression in India have given varied results $[2,3]$. India has inequitable mental health resource distribution with the majority of patients being undiagnosed of their mental diseases [4]. Women and the elderly have shown greater vulnerability to depression in India [3]. In India, housewives play a major role in family and society. Additional responsibilities due to modernization in rural areas have to lead to increased stress and tension among housewives [5]. Depression is a complex phenomenon and there is no single factor that can explain the cause for depression. Life events like separation, divorce, domestic violence, family disputes, etc. affect health
Adversely. Women are more likely to internalize conflict resulting in depression and anxiety. Limited data is available on depression among housewives in rural India especially Uttar Pradesh. Further, disparities exist in access to mental health facilities in rural areas [6]. There is a need for estimating the disease burden in areas where community-based studies on mental health have not been conducted. To improve the diagnosis, treatment, and prevention of depression in women, it is better to understand the etiology of depression in women; especially the biological, psychological and social origins of depression and better integrate data across these perspectives. So, the present study is planned to assess the prevalence of depression and its associated risk factors among housewives aged 1859 years in a rural area of district Saharanpur, Uttar Pradesh.

\section{Aim and Objectives}

Aim: To assess the prevalence of depression among housewives in the rural area.

\section{Objectives}

01. To assess the epidemiological co-relates of depression.

02. To identify the risk factors among housewives in the rural community.

03. To assess mental health help-seeking behavior in depressed subjects.

\section{Material and Methods}

Study Setting: The study was carried out in five villages of District Saharanpur, Uttar Pradesh. The villages are located in the rural field practice area of the Department of Community Medicine, SMMH Government Medical College, Saharanpur. There is the availability of psychiatrists at Government Medical College, Saharanpur and Medical Officer at Primary Health Centre Pilkhani for mental health help-seeking patients.

Study Period: The study was conducted from 01 November 2018 to 31 October 2019 (One Year).

Study Design: The present study was a descriptive cross-sectional community-based study.

Sampling Method: Five villages were randomly chosen among all villages in the rural field practice area.

The minimum sample size required for the study was calculated as follows: 
$N=\underline{Z 2} \underline{p}(\underline{1-p})$

D2

Where

$\mathrm{N}=$ sample size

$\mathrm{P}=$ expected prevalence or proportion

$\mathrm{D}=$ precision rate

As data on the prevalence of depression was not available for rural Saharanpur, p was taken as $50 \%$ which gives the maximum sample size for doing prevalence study [7].

Hereby taking,

$Z=1.96$

$P=50(=0.5)$

$D=0.05$

$\mathrm{N}=(\underline{1.96}) \underline{2}(\underline{0.5})(\underline{1-0.5})$

$(0.05) 2$

$N=384$

Allowing for a non-response rate of $20 \%$, the sample size comes to be 461 . Thus, the current study included 500 subjects in the present study. A total of 500 housewives were selected by systematic random sampling with the first subject selected randomly by the currency note method. Subsequent subjects were selected as per sampling interval.

Ethical Consideration and permission: Informed written consent was taken from interviewed adult housewives after explaining to them the purpose of the study. If they refused to participate in the study or the house was locked the adjacent house was substituted in its place. The study was duly approved by the Institutional Ethics Committee of SMMH Government Medical College, Saharanpur.

\section{Inclusion criteria}

01. Randomly selected housewives aged 18-59 years willing to participate in the study.

02. Able to understand and respond to the questionnaire.

\section{Exclusion criteria}

01. Refusal to

02. Locked house.

03. Housewives already diagnosed with any psychiatric disorders.
04. Housewives in the antepartum and postpartum period.

The procedure of data collection: A pretested proforma was used. Interviews were conducted by the house to house visits. Each individual was told about the purpose of the study and confidentiality of information was assured.

Development of Proforma: The proforma was developed according to rural Indian scenarios according to suggestions of senior faculty members of the Department of Community Medicine, SMMH Government Medical College, Saharanpur. The socio-economic status (SES) was determined by the Modified Udai Pareek (MUP) scale. Based on the MUP score, the SES was divided into 4 categories. Depression was evaluated using the self-reported instrument Patient Health Questionnaire-9 (PHQ-9) [8]. The questionnaire comprises of nine items, each is scored 0 to 3 , which yields a severity score from 0 and 27. Subject with a PHQ-9 score of 10 or higher was assessed as having at least moderate depression, as per international norms for PHQ-9. The reliability and validity of the scale have already been established [9-11]. Mental health help-seeking behavior was asked and noted. The subjects screened to be having at least moderate depression were given information on depression and were advised to visit psychiatrists at Government Medical College, Saharanpur.

Statistical methods and analysis: The data obtained were tabulated and analyzed by using descriptive statistics, viz. Percentages with the help of MS Excel software and SPSS software version 22. Yates' p-value $<0.05$ was considered statistically significant.

\section{Results}

A total of 500 subjects were included in the study. On the evaluation of PHQ-9 proforma, the prevalence of depression was found to be $18 \%$ ( 90 subjects) (Figure 1).

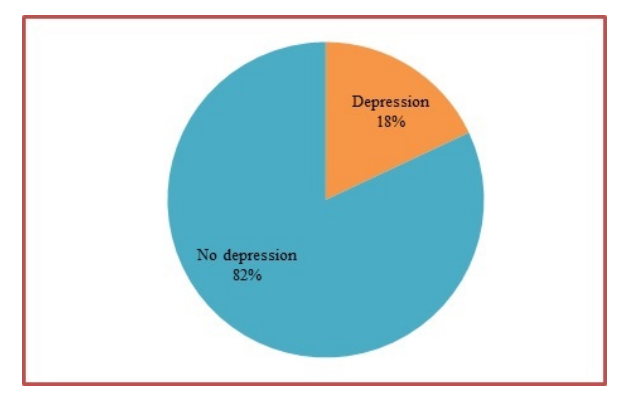

Fig-1: Prevalence of Depression as per Patient 


\section{Health Questionnaire-9.}

Among the 500 subjects interviewed, 118 (23.6\%) subjects were in the age of $18-29$ years, 172 $(34.4 \%)$ in $30-39$ years, $141(28.2 \%)$ in $40-49$ years and $69(13.8 \%)$ were in the age group of 50 59 years. The mean age of the subjects was $34.69 \pm 11.38$ years. The mean age of depressed subjects was found to be $38.52 \pm 10.14$ years. The prevalence of depression was found to be $9.3 \%$ in the age of $18-29$ years, $16.9 \%$ in $30-39$ years, $24.1 \%$ in $40-49$ years and $23.2 \%$ in the age group of 50-59 years. There was an increasing trend in the prevalence of depression in the middle age group.
The difference was found to be statistically significant. ( $p=0.02$ ) (Table 1 ). The majority of subjects $(83 \%)$ were currently married. The prevalence of depression was $15.4 \%$ in currently married, while it was twice in Widow or Separated or Never Married subjects (30.6\%). The comparison with respect to marital status was found to be statistically significant $(p=0.02)$ (Table 1$)$. One-third of subjects i.e. 168 (33.6\%) had no schooling. There were 143 (28.6\%) subjects who had primary schooling, $110(22.0 \%)$ subjects with secondary schooling and 79 (15.8\%) with an above secondary level of education.

Table-1: Demographic characteristics and risk factors of study participants.

\begin{tabular}{|c|c|c|c|c|}
\hline $\begin{array}{l}\text { Socio-demographic } \\
\text { characteristics }\end{array}$ & $\begin{array}{l}\text { Frequency }(\%) \\
\qquad(\mathrm{n}=500)\end{array}$ & $\begin{array}{l}\text { Prevalence of Depression }(\%)(\mathrm{n}= \\
\text { Frequency) }\end{array}$ & $\begin{array}{l}\text { No Depression }(\%)(\mathrm{n}= \\
\text { Frequency })\end{array}$ & $\begin{array}{l}\mathrm{p}- \\
\text { Value }\end{array}$ \\
\hline \multicolumn{5}{|l|}{ Age (Years) } \\
\hline $18-29$ & $118(23.6)$ & $11(09.3)$ & $107(90.7)$ & \multirow[t]{4}{*}{0.02} \\
\hline 30-39 & $172(34.4)$ & $29(16.9)$ & $143(83.1)$ & \\
\hline 40-49 & $141(28.2)$ & $34(24.1)$ & $107(75.9)$ & \\
\hline $50-59$ & $69(13.8)$ & $16(23.2)$ & $53(76.8)$ & \\
\hline \multicolumn{5}{|l|}{ Marital Status } \\
\hline Currently Married & $415(83)$ & $64(15.4)$ & $351(84.6)$ & \multirow[t]{2}{*}{0.02} \\
\hline Widow/ Separated/ Never Married & $85(17)$ & $26(30.6)$ & $59(69.4)$ & \\
\hline \multicolumn{5}{|l|}{ Educational Status } \\
\hline Unschooled & $168(33.6)$ & $41(24.4)$ & $127(75.6)$ & \multirow[t]{4}{*}{0.01} \\
\hline Primary & $143(28.6)$ & $28(19.6)$ & $115(80.4)$ & \\
\hline Secondary & $110(22.0)$ & $15(13.6)$ & $95(86.4)$ & \\
\hline Above Secondary & $79(15.8)$ & $06(7.6)$ & $73(92.4)$ & \\
\hline \multicolumn{5}{|l|}{ Socio-economic Status } \\
\hline Low & $52(10.4)$ & $16(30.8)$ & $36(69.2)$ & \multirow[t]{4}{*}{0.01} \\
\hline Low middle & $274(54.8)$ & $55(20.1)$ & 219 (79.9) & \\
\hline High middle & $132(26.4)$ & $15(11.4)$ & $117(88.6)$ & \\
\hline High & $42(8.4)$ & $4(9.5)$ & $38(90.5)$ & \\
\hline \multicolumn{5}{|l|}{ Debt on household } \\
\hline Present & $84(16.8)$ & $23(27.4)$ & $61(72.6)$ & \multirow[t]{2}{*}{0.02} \\
\hline Not Present & $416(83.2)$ & $67(16.1)$ & 349 (83.9) & \\
\hline \multicolumn{5}{|l|}{ Economic Dependence } \\
\hline Independent & $63(12.6)$ & 05 (7.9) & $58(92.1)$ & \multirow[t]{2}{*}{0.04} \\
\hline Dependent & $437(87.4)$ & 85 (19.5) & $352(80.5)$ & \\
\hline \multicolumn{5}{|c|}{ History of any Co-morbid conditions/chronic disease } \\
\hline Present & $117(23.6)$ & $29(24.8)$ & $88(75.2)$ & \multirow[t]{2}{*}{0.04} \\
\hline Not Present & $383(76.6)$ & $61(15.9)$ & $322(84.1)$ & \\
\hline
\end{tabular}

An inverse relationship was found between depression and level of education and this difference was observed to be statistically significant $(p=0.01)$ (Table 1 ). More than half of the subjects $(54.8 \%)$ were from the Low middle socio-economic group.
Low (10.4\%), High middle (26.4\%) and High $(8.4 \%)$ socio-economic status groups comprised the rest of the subjects. Lower socioeconomic status was significantly found to be associated with higher rates of depression $(p=0.01)$. The subjects that had 
Any debt on their household had a higher prevalence of depression (27.4\%) compared to subjects that had no debt $(16.1 \%)$ and the difference was statistically significant $(p=0.02)$. Economically independent women had significantly $(p=0.04)$ lower prevalence of depression $(7.9 \%)$ than economically dependent women (19.5\%). The subjects that had a history of any Co-morbid conditions/chronic disease had significantly $(p=0.04)$ higher rates of depression $(24.8 \%)$ than normal subjects (15.9\%) (Table 1 ). Out of a total 90 subjects screened to be having at least moderate depression, none had visited a mental health help facility in the last 6 months. None of them had ever received any therapy for depression.

\section{Discussion}

The prevalence of depression among women 18-59 years age was found to be $18 \%$ in the current study. A study by Poongothai et al. on the prevalence of depression in urban Chennai, South India in 2009 found a prevalence of $16.3 \%$ in females which is comparable to the present study [12]. However, a study by Urvashi et al. at rural Ludhiana, Punjab from March 2014 to February 2015 on 300 female subjects observed the prevalence of depression was 43\% [13]. Mathias et al. in July 2014 conducted a cross-sectional study on depression and help-seeking in Uttarakhand, North India on 960 subjects found overall 6\% prevalence of depression and $7.9 \%$ prevalence in female subjects [14]. A study by Deswal et al. in the urban community of Pune, Maharashtra in 2012 found the overall prevalence of depression to be $3.14 \%$ [15]. Another study by Obadeji et al. conducted in a Primary Care Setting in Nigeria in 2015 observed the prevalence of depression to be $47.8 \%$ [16]. The study by Nisar et al. (2004) on adult women in a fishing community in Pakistan found a point prevalence of depressive disorder was $7.5 \%$ [17]. The reason for the wide variation in prevalence can be the rural-urban difference in the study populations, a screening tool used and the regional variation. The present study revealed that there was an increasing trend of prevalence of depression in the middle age group. A study by Mathias et al. observed people in their middle years had a slightly higher risk of depression than those under 30 years and over 50 years of age [14]. A study by Urvashi et al. observed an increasing trend of depression among housewives with increasing age [13]. Poongothai et al. reported an increasing trend in the prevalence of depression among female
Subjects with age [12]. Obadeji et al. found a significantly higher prevalence of depression among subjects aged $\geq 45$ years [16]. Advancing age has a direct relationship with depression and was also reported in several studies in Pakistan by Nisar et al., Mumford et al, Husain et al and Ali et al [1720]. In the present study, the mean age of depressed subjects was found to be 38.52 10.14 years. A study by Urvashi et al. observed the mean age of subjects with depression to be $42.4 \pm 10.3$ years [13]. In the present study, married subjects had a lower prevalence of depression. A study by Urvashi et al. also observed a similar finding [13]. Poongothai et al. and Obadeji et al. also reported an increasing trend in the prevalence of depression among divorced, separated or widowed subjects $[12,16]$. The most likely explanation for the association with being widowed or divorced is related to increased stress and socio cultural practices. In the present study, the risk of depression increased with decreasing educational status. A study by Urvashi et al. also found an inverse relationship between the level of education and depression and observed education has an important influence on psychosocial characteristics such as efficacy and self-esteem both of which have a moderator effect on depression [13]. Research findings of Mathias et al. suggested a dose-response relationship in educational status, with the risk of depression increases with decreasing years of completed schooling [14]. Similar findings were also observed by Deswal et al. and Ali et al. $[15,20]$. The current study observed that depression was more prevalent in lower socio-economy groups. The study by Mathias et al. observed a greater risk of depression for the poorest [14]. A study by Urvashi et al. also found lower socio-economic status to be associated with higher rates of depression [13]. Poongothai et al. also reported that the prevalence of depression was higher in the low-income group [12]. In the present study, the subjects that had any debt on their household had a higher prevalence of depression. A study by Mathias et al. also observed a greater risk of depression for subjects who had taken a recent loan [14]. In the present study, economically independent women had lower rates of depression. A study by Chauhan et al. in rural South India from September 2010 to March 2011 on 290 elderly subjects observed the prevalence of depression significantly lower in economically independent subjects [21]. The present study observed that subjects that had a history of any co-morbid conditions/chronic disease had significantly higher rates of depression. Patel et 
Al in their population-based cohort study on 2494 women aged 18 to 50 years on risk factors of common mental disorders in Goa reported a significant association between chronic physical illness and common mental disorders [22]. Luni et al in their study on the prevalence of depression and anxiety in a village in Sindh, Pakistan on 260 people found a strong association between chronic illness and depression [23]. In the current study, none of the subjects screened to be having at least moderate depression had visited a mental health help facility in the last 6 months. None of them had ever received any therapy for depression. A study by Mathias et al. only two people had visited a mental health service provider in the previous 3 months, and no one had received talking therapy, indicating a treatment gap of $100 \%$ for the recommended first-line treatment of mild or moderate depression [14].

Recommendations: Screening of the community for mental health issues and giving information on depression can lead to them to visiting psychiatrist. Health education on the mental health of rural people is important to create awareness, motivation and generate help-seeking behavior.

\section{Limitations}

The present study estimates the prevalence through PHQ-9. This questionnaire is a screening tool. Definitive diagnosis by Psychiatrists would have greater accuracy. The study design is cross-sectional and thus causality cannot be established. Further, the study was undertaken with a small sample in a rural area of Saharanpur and may not be representative of the entire rural population.

\section{Conclusion}

Depression is a serious and common mental condition. Depression may occur at any age during a women's life irrespective of educational and economic status. The present study found the prevalence of depression to be $18 \%$. There was an increasing trend of prevalence of depression in the middle age group. The increasing level of education, marriage, better socio-economy, economic independence and absence of co-morbid conditions were having a lower prevalence of depression. None of the depressed subjects had taken professional help. Housewives should be educated about warning signs and symptoms of depression and motivated to seek professional help.

\section{What does the study add to the existing knowledge}

The study adds to our understanding of depression and its risk factors. The study would be a guide for further community-based research for mental health with large samples involving almost all age groups in various parts of the country for diagnosing and counseling the unseen cases.

\section{Author's contribution}

Dr. Bibhava Vikramaditya: Principal investigator and wrote the manuscript. Dr. Amit Kumar Jha: Designed the study, guided in finalization of the manuscript and proforma development and review.

Dr. Sanjeev Kumar: Guided in editing the manuscript for corrections and proforma development and review. Dr. Manjeeta: Data collection and data tabulation. Dr. Hari Shankar Joshi: Guided in editing manuscript for corrections and proforma development and review.

\section{Acknowledgments}

Authors are thankful to the staff at PHC, Pilkhani and local leaders for their support.

\section{Reference}

01. Whiteford HA, Degenhardt L, Rehm J, Baxter AJ, Ferrari $A J$, Erskine $H E$, et al. Global burden of disease attributable to mental and substance use disorders findings from the Global Burden of Disease $\quad 2010 . \quad$ Ltudy 2 Lancet. 2013;382(9904)1575-1586.

doi: [Article] [Crossref]

02. Math S, Chandrashekar CR, Bhugra D. Psychiatric epidemiology in India. Indian J Med Res. 2007;126(3)183-192.

[Crossref]

03. Ganguli HC. Epidemiological findings on the prevalence of mental disorders in India. Indian J Psychiatry. 2000;42(1)14-20. [Crossref]

04. World Health Organization. Mental health atlas 2011. Geneva- WHO. [Internet] 2011 [cited 2019 Dec 20]. Available at: [Article][Crossref]

05. Kessler RC. Epidemiology of women and depression. J Affect Dis. 2003;74(1)5-13. doi: [Article] [Crossref] 
06. Reddy VM, Chandrashekar CR. Prevalence of mental and behavioural disorders in India- a meta-analysis. Indian J Psychiatry. 1998;40(2)149-157.

[Crossref]

07. Lemeshow S, Hosmer DW, Klar J, Lwanga SK. Adequacy of Sample Size in Health Studies. England- John Wiley \& Sons. 1990. Available from: [Article] [Crossref]

08. Kroenke K, Spitzer RL, Williams JB. The PHQ-9validity of a brief depression severity measure. J Gen Intern Med. 2001;16(9)606-613. doi: [Article] [Crossref]

09. Poongothai S, Pradeepa R, Ganesan A, Mohan V. Reliability and validity of a modified PHQ-9 item inventory (PHQ-12) as a screening instrument for assessing depression in Asian Indians (CURES-65). J Assoc Physicians India. 2009;57(2)147-152.

[Crossref]

10. Kochhar PH, Rajadhyaksha SS, Suvarna VR. Translation and validation of brief patient health questionnaire against DSM IV as a tool to diagnose major depressive disorder in Indian patients. J Postgrad Med. 2007;53(2)102-107. doi: [Article] [Crossref]

11. Kroenke K, Spitzer RL, Williams JB. The PHQ-9validity of a brief depression severity measure. J Gen Intern Med. 2001;16(9)606-613. doi: [Article] [Crossref]

12. Poongothai S, Pradeepa R, Ganesan A, Mohan V. Prevalence of depression in a large urban South Indian population the Chennai Urban Rural Epidemiology Study (CURES-70). PLoS ONE. 2009;4(9)e7185.

doi: [Article] [Crossref]

13. Urvashi, Girdhar S, Chaudhary A. Sociodemographic co-relates of depression among housewives in rural area of district Ludhiana. Int J Community Med Public Health. 2019;6(5)2147-51.

doi: [Article] [Crossref]

14. Mathias K, Goicolea I, Kermode M, Singh L, Shidhaye R, Sebastian MS. Cross-sectional study of depression and help-seeking in Uttarakhand, North India. BMJ Open. 2015;5(11)e008992.

doi: [Article] [Crossref]
15. Deswal BS, Pawar A. An epidemiological study of mental disorders at pune, maharashtra. Indian J Community Med. 2012;37(2)116-121. doi: [Article] [Crossref]

16. Obadeji A, Oluwole LO, Dada MU, Ajiboye AS, Kumolalo BJ, Solomon OA. Assessment of Depression in a Primary Care Setting in Nigeria using the PHQ 9. J Family Med Prim Care. 2015;4(1)30-4. doi: [Article] [Crossref]

17. Nisar N, Billoo N, Gadit AA. Prevalence of depression and the associated risks factors among adult women in a fishing community. J Pak Med Assoc. 2004;54(10)519-525.

[Crossref]

18. Mumford DB, Saeed K, Ahmad I, Latif S, Mubbashar $\mathrm{MH}$. Stress and psychiatric disorder in rural Punjab- A community survey. $\mathrm{Br} \mathrm{J}$ Psychiatry. 1997;170(5)473-478.

doi: [Article] [Crossref]

19. Husain N, Creed F, Tomenson B. Depression and social stress in Pakistan. Psychol Med. 2000;30(2)395-402.

doi: [Article] [Crossref]

20. Ali TS, Mogren I, Krantz G. Intimate partner violence and mental health effects- a population-based study among married women in Karachi, Pakistan. Int J Behav Med. 2013;20(1)131-139.

doi:10.1007/s12529-011-9201-6

[Crossref]

21. Chauhan P, Kokiwar PR, Shridevi K, Katkuri S. A study on prevalence and correlates of depression among elderly population of rural South India. Int J Community Med Public Health. 2016;3(1)236-239. doi: [Article] [Crossref]

22. Patel V, Kirkwood BR, Pednekar S, Weiss $H$, Mabey D. Risk factors for common mental disorders in women Population-based longitudinal study. $\mathrm{Br} \mathrm{J}$ Psychiatry. 2006;189(6)547-555. doi:10.1192/bjp.bp.106.022558 [Crossref]

23. Luni FK, Ansari B, Jawad A, Dawson A, Baig SM. Prevalence of depression and anxiety in a village in Sindh. J Ayub Med Coll Abbottabad. 2009;21(2)68-72.

[Crossref] 